\title{
Epigenetic modifications as key regulators of Waldenstrom's Macroglobulinemia biology
}

\author{
Antonio Sacco, Ghayas C Issa, Yong Zhang, Yang Liu, Patricia Maiso, Irene M Ghobrial, Aldo M Roccaro*
}

\begin{abstract}
Waldenstrom's Macroglobulinemia is a low-grade B-cell lymphoma characterized by the presence of lymphoplasmacytic cells in the bone marrow and a monoclonal immunoglobulin $\mathrm{M}$ in the circulation. Recent evidences support the hypothesis that epigenetic modifications lead to Waldesntrom cell proliferation and therefore play a crucial role in the pathogenesis of this disease. Indeed, while cytogenetic and gene expression analysis have demonstrated minimal changes; microRNA aberrations and modification in the histone acetylation status of primary Waldenstrom Macroglobulinemia tumor cells have been described. These findings provide a better understanding of the underlying molecular changes that lead to the initiation and progression of this disease.
\end{abstract}

\section{Introduction}

First introduced by C.H. Waddington in 1939 to name "the causal interactions between genes and their products, which bring the phenotype into being", the term "epigenetics" was later defined as heritable changes in gene expression that are not due to any alteration in the DNA sequence [1]. The best-known epigenetic markers are DNA methylation and histone acetylation. Moreover, all these phenomena are finely regulated in different manners, such as through microRNAs (miRNAs) [2].

Waldenström's Macroglobulinemia (WM) is a lowgrade B-cell lymphoma characterized by the presence of lymphoplasmacytic cells in the bone marrow (BM) and a monoclonal immunoglobulin $\mathrm{M}$ in the circulation $[3,4]$. The most common risk factor for WM is IgM MGUS (monoclonal gammopathy of undermined significance), which is associated with the presence of a small IgM protein in the circulation and minimal involvement $(<10 \%$ lymphoplasmacytic cells) in the bone marrow, with the absence of symptoms or signs of the disease. The risk of progression of IgM MGUS is the highest in all types of MGUS with about 5-10\% risk of progression per year.

While WM cells showed minimal changes at cytogenetic studies and gene expression analysis [5], primary WM tumor cells present with a miRNA signature that differentiates them from their normal counterpart. Among deregulated miRNAs, miRNA-155 has been

\footnotetext{
* Correspondence: aldo_roccaro@dfci.harvard.edu

Dana-Farber Cancer Institute, Medical Oncology, Harvard Medical School, Boston, MA, USA
}

shown to play a pivotal role in the biology of this disease both in vitro and in vivo. Moreover, other miRNA changes in WM cells, such as the down-regulation of miRNA-9*, has been proven to modulate the histone acetylation status in WM cells [6]. These findings support the idea that epigenetic modifications are crucial in the pathogenesis of WM. Importantly, these observation provide the preclinical rational for testing miRNA-based therapeutical approaches for the treatment of WM disease (Figure 1).

In this review, we will focus on the role of miRNAs and histone acetylation as key regulators of WM biology.

miRNA signature characterizes primary WM tumor cells miRNAs constitute a class of small, non-coding, 18-24 nucleotide RNAs, described for the first time in the nematode Caenorhabditis elegans [7]. By repressing several target mRNAs, mature miRNAs play a pivotal role in regulating development, cell differentiation, apoptosis, and cell proliferation [8-10]. Importantly, miRNAs have been described to play roles in both solid tumors and hematologic malignancies [11-13]. We have recently performed miRNA studies in WM, and through unsupervised clustering, we showed that WM clonal cells present with a miRNA signature that differs from that of their normal counterpart. Importantly, seven miRNAs were specifically different between WM patients and healthy individuals: among them, miRNA-363*, -206, $-494,-155,-184,-542-3 p$ demonstrated increased expression in WM patients; whereas miRNA-9* 


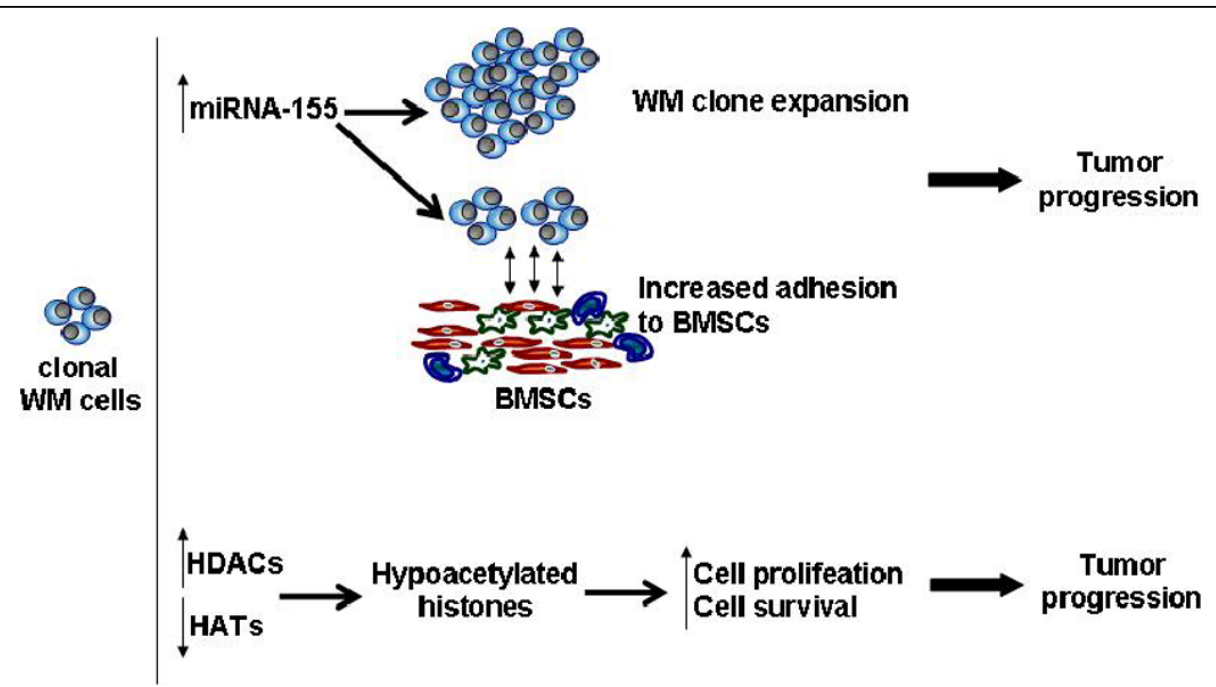

Figure 1 miRNA aberrations and hypoacetylated histones drive WM pathogenesis. WM tumor cells present with increased level of miRNA155, together with increased expression of HDACs and reduced expression of HATs, leading WM clone expansion and tumor progression. (BMSCs: bone marrow stromal cells: miRNA-155: microRNA-155; HDAC: histone deacetylase; HAT: histone acetyltransferase)

demonstrated decreased expression in WM patients. Predicted targets of the increased miRNAs in WM patients included tumor suppressors, cell cycle inhibitors, cytokine signaling suppressors and tyrosine phosphatases. Conversely, predicted target genes for the decreased miRNAs in WM included protein kinases, oncogenes and transcription factors. In addition, we showed that several protein kinases, transcription factors, and cell cycle regulators were up-regulated in WM patients including protein kinase $\mathrm{C}$, serine/threonine kinase 24 , mitogen-activated protein kinase kinase kinase 7, E2F- and pre-B-cell leukemia-transcription factors, as well as cyclin D2 and cyclin-dependent kinase inhibitor [14], suggesting that miRNAs may play a crucial role in WM pathogenesis.

miRNA-155 is expressed from an exon of the noncoding BIC gene [15]. Its role as oncogenic miRNA and its involvement in the initiation and progression of cancers has been reported in several hematologic malignancies, including diffuse large B-cell lymphomas, chronic lymphocytic leukemia and primary mediastinal B-cell lymphomas, where it has shown to be highly expressed [16-18]. Based on the evidence that miRNA-155 is increased in primary WM cells, we subsequently conducted in vitro and in vivo studies to better define the functional and biological role of miRNA-155 in supporting WM cell pathogenesis; and it has been demonstrated that DNA synthesis was significantly reduced in miRNA-155 knocked-down cells compared to control cells [14]. Similarly, miRNA-155 modulated cell cycle progression in WM cells, as demonstrated by an increased \% of cells in G1-phase, together with a decreased \% of cells in S-phase. These findings were validated at gene expression profiling that showed increased expression of cyclin-dependent kinase inhibitors (p18, p19, p21, p27); decreased expression of cyclin-dependent kinases-2, $-4,-6$, as well as cyclins D1, D2, D3 and E; and increased expression of p53 with decreased expression of its negative regulator $(\mathrm{Mdm} 2)$ in the miRNA-155 knockdown WM cells compared to controls. In addition, the impact of miRNA-155 knockdown on signaling cascades regulating proliferation was next investigated showing that miRNA-155 knockdown strongly inhibited ERK- and AKT-phosphorylation, as well as p-GSK3 $\alpha / \beta$ and p-S6R, both AKT downstream target proteins.

It has been clearly demonstrated that BM microenvironment confers growth advantages to and induces drug resistance in malignant cells [19]. Therefore, the role of miRNA-155 in regulating WM cell proliferation in the context of BM milieu has been investigated, showing a significant inhibition of adhesion to fibronectin in miRNA-155 knockdown cells compared to controls. These findings were also supported by downregulation of genes such as Rho GTPase activating proteins, p21 (CDKN1A) activating protein, and p21-activated kinase (PAK)-1 interacting protein, which are known to be involved in the adhesion process [20]. Similarly, miRNA-155 knockdown significantly inhibited WM cell migration in response to stromal derived factor-1 (SDF1 ), an important regulator of migration in B cells. In addition, while adherence of both non-transfected or control probe-transfected WM cells to BM stromal cells triggered 34\% and 33\% increase in proliferation, any significant increase in the proliferation rate of miRNA-155 knocked down WM cells has been described, indicating 
that they overcome the growth advantage from of BM milieu. To better support the in vitro findings, effect of miRNA-155 in regulating WM cell migration was also confirmed in vivo, by using an in vivo homing model [21]. In addition, mice injected with miRNA-155 knockdown probe-transfected WM cells had prolonged survival compared with mice injected with control probetransfected WM cells, with mean survival of 20 days vs 14 days $(\mathrm{P}<.001)$ and overall survival of 21 days vs 15 days, respectively.

WM cells present with a hypoacetylated status of histone, partially driven by miRNA aberrations in the clonal WM cell population

Histone acetylation is commonly deregulated in several tumors. Nucleosomal histone acetylation homeostasis is responsible for the transcriptional regulation of many genes: particularly, hypoacetylation is associated with a condensed chromatin structure leading to the repression of gene transcription; while, hyperacetylation is associated with a more open chromatin structure and activation of transcription [22,23]. This balance is modulated by a tight regulation of histone deacetylase (HDAC) and histone acetyl transferases (HATs) levels. In many malignancies, this balance is deregulated; and tumor cells present with an increased expression of HDACs leading to decreased gene transcription $[7,8]$. HDACs are enzymes that catalyze the removal of the acetyl modification on lysine residues of proteins, including the nucleosomal histones $\mathrm{H} 2 \mathrm{~A}, \mathrm{H} 2 \mathrm{~B}, \mathrm{H} 3$, and $\mathrm{H} 4$. In addition, other induced genes include the cell cycle kinase inhibitor $\mathrm{p} 21^{\mathrm{WAF} 1}, \mathrm{p} 16^{\text {ink4a }}$, and $\mathrm{p} 27^{\mathrm{Kip}}, \mathrm{p} 53$, NFYA, and GATA-1, leading to enhanced cellular functions such as proliferation, cell-cycle, and survival [24].

Alterations in the balance between HAT and HDAC activity in many cancers will lead to deregulated gene expression and the induction of proliferation and survival in tumor cells $[25,26]$. HDACs mediate the function of oncogenic translocations in many malignancies including promyelocytic (PML)-retinoic acid receptor alpha $(\mathrm{RAR} \alpha)$ in acute promyelocytic leukemia [27]. Most of the aberrant HAT and HDAC activity has been due to translocation, amplification, overexpression or mutation in many malignancies, including hematological malignancies $[25,26,28]$. Recent studies have demonstrated that miRNAs may exert their activity by interfering with the epigenetic machinery, such as modulating the expression of enzymes regulating DNA methylation or histone modification [27-30]. For example, it has been demonstrated that up-regulation of miRNA-449a in prostate cancer cells exerts an anti-proliferative effect on the tumor clone, supported by cell cycle arrest and induction of a senescence-like phenotype and apoptosis [30]. In addition, other miRNAs are responsible for targeting histone methyltransferases. It has been recently reported that miRNA-101 targets the enhancer of Zeste homolog 2 (EZH2); the low expression level in several tumor types could lead to up-regulation of EZH2 in aggressive tumors with an invasive phenotype [31,32].

Recent studies have focused on the histone acetylation status in WM cells and how miRNA may be responsible for regulating histone acetylation in this disease. miRNA-206 and $-9^{*}$ are respectively increased and decreased in WM cells, as compared to normal cells [14]. Predicted targets for the increased miRNA-206 and decreased miRNA-9* included histone-acetyltransferases (HATs) and HDACs, respectively, suggesting a possible role of miRNA-206 and $-9 *$ in regulating histone acetylation in WM. Indeed, primary WM cells were characterized by significant increased expression of HDAC-2, $-4,-5,-6,-8,-9$, and significant decreased expression of HAT $-1,-2$, and -3 ; together with a significantly higher HDAC activity as compared to controls. Importantly, functional studies revealed that acetyl histone- $\mathrm{H} 3$ and -H4 were upregulated in pre-miRNA-9*- and -antimiRNA-206-transfected cells, with a higher acetyl histone-H3 and -H4 up-regulation upon miRNA-9* modulation. Moreover, miRNA-9*-dependent modulation of HDAC activity lead to reduced WM cell proliferation and increased WM cell toxicity, suggesting a key role of miRNA-9* in regulation WM progression [6].

\section{Conclusions}

Modifications at the level of miRNAs have recently gained considerable attention in the field of cancer research. It has been recently identified an increased expression of miRNAs-363*, -206, -494, -155, -184, $-542-3 p$, and decreased expression of miRNA-9* in primary bone marrow-derived WM tumor cells. Based on this first observation, functional studies have been focused on miRNA-155, and the oncogenic role of miRNA-155 has been confirmed and validated in WM cells. Indeed, miRNA-155 acts as a critical regulator of proliferation of WM cells, where it specifically targets WM cells even in the context of a bone marrow milieu. This provides preclinical evidences to enhance our understanding about the role of epigenetic changes in WM pathogenesis. Indeed, if cytogenetic and molecular studies on gene expression analysis at the miRNA level have demonstrated minimal changes in WM cells, the described significant differences in WM miRNA expression profiling improve our understanding of the underlying molecular changes that lead to the initiation and progression of this rare disease. Importantly, miRNA155 may be regarded as a sufficiently restricted therapeutic target in WM.

In addition, subsequent studies have demonstrated that that loss of miRNA-9* may be responsible for 
up-regulation of HDAC4 and HDAC5 in primary WM cells, contributing to the pathogenesis of this disease; this also indicates the potential therapeutic value of synthetic miRNA oligonucleotides as epigenetic modulators with a mechanism of action similar to chemical HDAC inhibitors.

\section{Authors' contributions}

AS, GCl, YZ, YL, PM: wrote the manuscript.

IMG, AMR: revised the manuscript.

All authors read and approved the final manuscript.

\section{Competing interests}

The authors declare that they have no competing interests.

Received: 14 September 2010 Accepted: 7 October 2010

Published: 7 October 2010

\section{References}

1. Waddington $\mathrm{CH}$ : Preliminary notes on the development of the wings in normal and mutant strains of drosophila. Proc Natl Acad Sci USA 1939, 25:299-307.

2. Mack GS: Epigenetic cancer therapy makes headway. J Natl Cancer Inst 2006, 98:1443-1444.

3. Ghobrial IM, Gertz MA, Fonseca R: Waldenstrm macroglobulinaemia. Lancet Oncol 2003, 4:679-685

4. Owen RG, Treon SP, Al-Katib A, Fonseca R, Greipp PR, McMaster ML Morra E, Pangalis GA, San Miguel JF, Branagan AR, Dimopoulos MA: Clinicopathological definition of Waldenström's macroglobulinemia: consensus panel recommendations from the Second International Workshop on Waldenström's Macroglobulinemia. Semin Oncol 2003, 30:110-115.

5. Chng WJ, Schop RF, Price-Troska T, Ghobrial I, Kay N, Jelinek DF, Gertz MA Dispenzieri A, Lacy M, Kyle RA, Greipp PR, Tschumper RC, Fonseca R, Bergsagel PL: Gene expression profiling of Waldenström's macroglobulinemia reveals a phenotype more similar to chronic lymphocytic leukemia than multiple myeloma. Blood 2006, 108:2755-2763.

6. Roccaro AM, Sacco A, Jia X, Azab AK, Maiso P, Ngo HT, Azab F, Runnels J, Quang P, Ghobrial IM: microRNA-dependent modulation of histone acetylation in Waldenstrom macroglobulinemia. Blood 2010, 116:1506-1514

7. Lee RC, Feinbaum RL, Ambros V: The C-Elegans heterochronic gene Lin-4 encodes small RNAs with antisense complementarity to Lin-14. Cell 1993, 75:843-854.

8. Xie X, Lu J, Kulbokas EJ, Golub TR, Mootha V, Lindblad-Toh K, Lander ES, Kellis M: Systematic discovery of regulatory motifs in human promoters and 3 'UTRs by comparison of several mammals. Nature 2005 434:338-345.

9. He L, Hannon GJ: MicroRNAs: small RNAs with a big role in gene regulation. Nat Rev Genet 2004, 5:522-531.

10. Roldo C, Missiaglia E, Hagan JP, Falconi M, Capelli P, Bersani S, Calin GA, Volinia S, Liu CG, Scarpa A, Croce CM: MicroRNA expression abnormalities in pancreatic endocrine and acinar tumors are associated with distinctive pathologic features and clinical behaviour. J Clin Oncol 2006, 24:4677-4684.

11. Lu J, Getz g, Miska EA, Alvarez-Saavedra E, Lamb J, Peck D, SweetCordero A, Ebert BL, Mak RH, Ferrando AA, Downing JR, Jacks T, Horvitz HR, Golub TR: MicroRNA expression profiles classify human cancers. Nature 2005, 435:834-838

12. Iorio MV, Ferracin M, Liu CG, Veronese A, Spizzo R, Sabbioni S, Magri E, Pedriali M, Fabbri M, Campiglio M, Ménard S, Palazzo JP, Rosenberg A Musiani P, Volinia S, Nenci I, Calin GA, Querzoli P, Negrini M, Croce CM: MicroRNA gene expression deregulation in human breast cancer. Cancer Res 2005, 65:7065-7070.

13. Calin GA, Liu CG, Sevignani C, Ferracin M, Felli N, Dumitru CD, Shimizu M, Cimmino A, Zupo S, Dono M, Dell'Aquila ML, Alder H, Rassenti L, Kipps TJ, Bullrich F, Negrini M, Croce CM: MicroRNA profiling reveals distinctive signatures in B cell chronic lymphocytic leukemias. Proc Natl Acad Sci USA 2004, 101:11755-11760.

14. Roccaro AM, Sacco A, Chen C, Runnels J, Leleu X, Azab F, Azab AK, Jia X, Ngo HT, Melhem MR, Burwick N, Varticovski L, Novina CD, Rollins BJ, Anderson $\mathrm{KC}$, Ghobrial IM: microRNA expression in the biology, prognosis and therapy of Waldenstrom Macroglobulinemia. Blood 2009, 113:4391-4402.

15. Tam W, Dahlberg JE: miR-155/BIC as an oncogenic microRNA. Genes Chromosomes Cancer 2006, 45:211-212.

16. Eis PS, Tam W, Sun L, Chadburn A, Li Z, Gomez MF, Lund E, Dahlberg JE: Accumulation of miR-155 and BIC RNA in human B cell lymphomas. Proc Natl Acad Sci USA 2005, 102:3627-3632.

17. Rai D, Karanti S, Jung I, Dahia PL, Aguiar RC: Coordinated expression of microRNA-155 and predicted target genes in diffuse large B-cell lymphoma. Cancer Genet Cytogenet 2008, 181:8-15.

18. Kluvier J, Poppema S, de Jong D, Blokzij T, Harms G, Jacobs S, Kroesen BJ, van den Berg A: BIC and miR-155 are highly expressed in Hodgkin, primary mediastinal and diffuse large B cell lymphomas. J Pathol 2005, 207:243-249

19. Mitsiades CS, Mitsiades NS, Munshi NC, Richardson PG, Anderson KC: The role of the bone microenvironment in the pathophysiology and therapeutic management of multiple myeloma: interplay of growth factors, their receptors and stromal interactions. Eur J Cancer 2006, 42:1564-1573.

20. Chan PM, Lim L, Manser E: PAK is regulated by PI3K, PIX, Cdc42 and PP2Calpha and mediates focal adhesion turnover in the hyperosmotic stress-induced P38 pathway. J Biol Chem 2008, 283:24949-24961.

21. Alsayed $Y$, Ngo H, Runnels J, Leleu X, Singha UK, Pitsillides CM, Spencer JA Kimlinger T, Ghobrial JM, Jia X, Lu G, Timm M, Kumar A, Côté D, Veilleux I, Hedin KE, Roodman GD, Witzig TE, Kung AL, Hideshima T, Anderson KC, Lin CP, Ghobrial IM: Mechanisms of regulation of CXCR4/SDF-1 (CXCL12)dependent migration and homing in multiple myeloma. Blood 2007, 109:2708-2717

22. Mack GS: Epigenetic cancer therapy makes headway. J Natl Cancer Inst 2006, 98:1443-1444.

23. Bernstein BE, Meissner $A$, Lander ES: The mammalian epigenome. Cell 2007, 128:669-681.

24. Liu PY, Chan JY, Lin HC, Wang SL, Liu ST, Ho CL, Chang LC, Huang SM: Modulation of the cyclin-dependent kinase inhibitor p21(WAF1/Cip1) gene by Zac1 through the antagonistic regulators p53 and histone deacetylase 1 in HeLa Cells. Mol Cancer Res 2008, 6:1204-1214.

25. Bolden JE, Peart MJ, Johnstone RW: Anticancer activities of histone deacetylase inhibitors. Nat Rev Drug Discov 2006, 5:769-784.

26. Ropero S, Fraga MF, Ballestar E, Hamelin R, Yamamoto H, Boix-Chornet M, Caballero R, Alaminos M, Setien F, Paz MF, Herranz M, Palacios J, Arango D, Orntoft TF, Aaltonen LA, Schwartz S Jr, Esteller M: A truncating mutation of HDAC2 in human cancers confers resistance to histone deacetylase inhibition. Nat Genet 2006, 38:566-569.

27. Fabbri M, Garzon R, Cimmino A, Liu Z, Zanesi N, Callegari E, Liu S, Alder H, Costinean S, Fernandez-Cymering C, Volinia S, Guler G, Morrison CD, Chan KK, Marcucci G, Calin GA, Huebner K, Croce CM: MicroRNA-29 family reverts aberrant methylation in lung cancer by targeting DNA methyltransferases 3A and 3B. Proc Natl Acad Sci 2007, 140:15805-15810.

28. Cloos PA, Christensen J, Agger K, Maiolica A, Rappsilber J, Antal T, Hansen $\mathrm{KH}$, Helin $\mathrm{K}$ : The putative oncogene GASC1 demethylates tri- and dimethylated lysine 9 on histone H3. Nature 2006, 442:307-311.

29. Garzon R, Liu S, Fabbri M, Liu Z, Heaphy CE, Callegari E, Schwind S, Pang J, Yu J, Muthusamy N, Havelange V, Volinia S, Blum W, Rush LJ, Perrotti D, Andreeff M, Bloomfield CD, Byrd JC, Chan K, Wu LC, Croce CM, Marcucci G: MicroRNA-29b induces global DNA hypomethylation and tumor suppressor gene repression in acute myeloid leukemia by targeting directly DNMT3A and 3B and indirectly DNMT1. Blood 2009, 113:6411-6418

30. Noonan EJ, Place RF, Pookot D, Basak S, Whitson JM, Hirata H, Giardina C, Dahiya R: miR-449a targets HDAC-1 and induces growth arrest in prostate cancer. Oncogene 2009, 28:1714-1724.

31. Varambally S, Cao Q, Maini RS, Shankar S, Wang X, Ateeq B, Laxman B, Cao X, Jing X, Ramnarayanan K, Brenner JC, Yu J, Kim JH, Han B, Tan P, Kumar-Sinha C, Lonigro RJ, Palanisamy N, Maher CA, Chinnaiyan AM: Genomic loss of microRNA-101 leads to overexpression of histone methyltransferase EZH2 in cancer. Science 2008, 322:1695-1699. 
32. Friedman JM, Liang G, Liu CC, Wolff EM, Tsai YC, Ye W, Zhou X, Jones PA: The putative tumor suppressor microRNA-101 modulates the cancer epigenome by repressing the polycomb group protein EZH2. Cancer Res 2009, 69:2623-2629.

doi:10.1186/1756-8722-3-38

Cite this article as: Sacco et al:: Epigenetic modifications as key regulators of Waldenstrom's Macroglobulinemia biology. Journal of Hematology \& Oncology 2010 3:38.

Submit your next manuscript to BioMed Central and take full advantage of:

- Convenient online submission

- Thorough peer review

- No space constraints or color figure charges

- Immediate publication on acceptance

- Inclusion in PubMed, CAS, Scopus and Google Scholar

- Research which is freely available for redistribution

Submit your manuscript at www.biomedcentral.com/submit
C Biomed Central 